\title{
The Family Literacy Project: Sharing the pleasure of early literacy
}

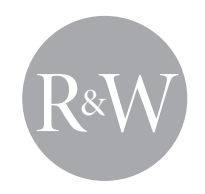

\author{
SNOEKS DESMOND Family Literacy Project
}

\begin{abstract}
The Family Literacy Project works with women in rural KwaZulu-Natal to help them improve their levels of literacy and provides encouragement as they support the literacy development of their children. These women have regularly visited neighbouring families to read to and play with children and discuss early childhood development and relevant health messages with adults. In addition community libraries and book boxes provide books for these under resourced areas. The findings of an independent evaluation are used to highlight aspects of the project.
\end{abstract}

\section{Background}

The Family Literacy Project ${ }^{1}$ (FLP) is a small non government organization working in sites within the southern Drakensberg area of KwaZulu-Natal. This is a World Heritage site, with spectacular scenery and many tourist attractions but daily life is difficult for the most of people who live there. According to the 2005 KwaZulu-Natal Municipal Portfolio, 17\% of the population in this area had no schooling and $41 \%$ are unemployed. The area is very under-resourced with the majority of homes having no access to electricity or adequate sanitation.

The Family Literacy Project was initiated in March 2000 as an attempt to improve literacy development in young children in this area and others across South Africa. The low level of literacy development in young children was one of the findings of the research into the national Early Childhood Development pilot project that showed that despite three years of support to pre-school teachers the literacy skills of children had not improved.

Findings of particular concern to me were that there was a decline in the early literacy and early numeracy assessment results over the three-year period for the Grade 1 and Grade R classes, and that

${ }^{1}$ For recent evaluations of the project and contact details of current FLP director: www. familyliteracyproject.co.za

READING AND WRITING 
only a quarter of community-based sites are offering 'high' quality education (Khulisa Management Services, 2000: iii).

One of the recommendations made by the research team was that "Grade $\mathrm{R}$ quality needs to be improved". In particular, the team felt that the "low early literacy and somewhat higher early numeracy assessment results show that educators are not spending enough time on literacy and numeracy tasks and, even more importantly, have not mastered the methodologies for passing these skills on to the learners" (Khulisa Management Services 2000: iii).

The team made a number of recommendations on how to improve the quality of Grade R service, one of which was that more books and educational equipment should be provided in the classrooms. The report stated that "the presence of accessible books is highly correlated with improved early literacy assessment results" (Khulisa Management Services, 2000: viii).

As a senior member of the research team, I pre-tested the assessment instrument, was in charge of drafting the interview instruments, trained the fieldworkers, conducted fieldwork and assisted in the report-writing. I was concerned that by the end of the three-year pilot project, there had not been a more significant improvement in the early literacy assessment scores (Desmond, 2001: 2-3).

The Family Literacy Project was established in an attempt to find a different way to support the early literacy development of young children. The approach selected was to support parents in their role as the first and most important educators of children. There are different expressions of family literacy and the approach of the FLP is in line with the following definition by the National Literacy Trust that "family literacy (is) any programme or initiative that aims to work through parents to improve the reading and writing of their children, as well as those that have the improvement of the parent's literacy as an aim" (National Literacy Trust, undated).

\section{Implementing the project}

During the first year of the project, monthly workshops were held for parents and other caregivers of the children attending the nearby pre-school or crèche in five sites in KwaZulu-Natal. One of the questions parents were asked was what they thought children should learn at pre-school. The answers included the wish for their children to learn respect, to learn to speak Zulu well, to be creative, to say rhymes and to write or at least know how to hold a pen. When asked how they could help prepare their children for pre-school or primary 
school, the adults said they did not think that they could do very much, especially as many of them could not read or write well, or even at all. This need to build parental confidence guided the design of the workshops throughout that year.

The understanding that parents are the 'first' teachers of their own children is one widely held in the early childhood development sector but one which is often not put into practice. Instead, pre-schools and crèches become seen as the places where children learn. The FLP workshops centred on how early literacy development starts at birth and how parents can help their young children. The role of the parent at this stage does not require that they be literate as the interactions with the baby will be through spoken language. Parents can talk and listen to their children, they can provide an environment rich in language that lays the foundation for early literacy development, without their being able to read or write a word (Desmond, 2007).

Gradually, in that first year, parents' confidence developed as they realised that through everyday tasks they could help prepare their children to learn to read:

Exposure to written material is critical to preschool children for their literacy development but while there are one million children living in households with no literate adults, we have to look at other ways of providing developmental support. We should be encouraging everyday opportunities in the home to be used to link words to activities, events, people and objects and clarifying the link between them in the present as well as in the future and the past (Richter, 2006).

By talking to a child as they went to the river to fetch water and discussing this when they reached home, parents helped develop skills of sequencing, recall, repetition and improved vocabulary. When travelling to the village by taxi they pointed out signs and discussed advertisements. They praised their children for bringing all the cattle home safely and for being able to describe the different markings. They made links between events and memories of previous events experienced by the children. They pointed out colours, shapes and sizes around the home. The activities encouraged by the FLP gave life to the underlying assumption that parent-child conversations have a significant impact on a child's developing oral language skills (Dockrell et al., 2004).

By the end of that first year of workshops, the women requested help with their own literacy development. They selected women in their community and the Family Literacy Project provided training in the participatory Reflect approach, adult literacy and early literacy. The parents were attracted to the area of literacy development through their interest in helping their own 
children. Building on this interest the project then had to meet the expressed needs of the parents and a long-term group has emerged. Over the years others have joined and some have left but many of the original members are still attending as they have moved from basic literacy to learning English as an additional language.

The approach that was developed by the FLP is based on the following diagram which shows how it is participatory, has an action point, and how teaching on early literacy support is integrated with adult literacy.

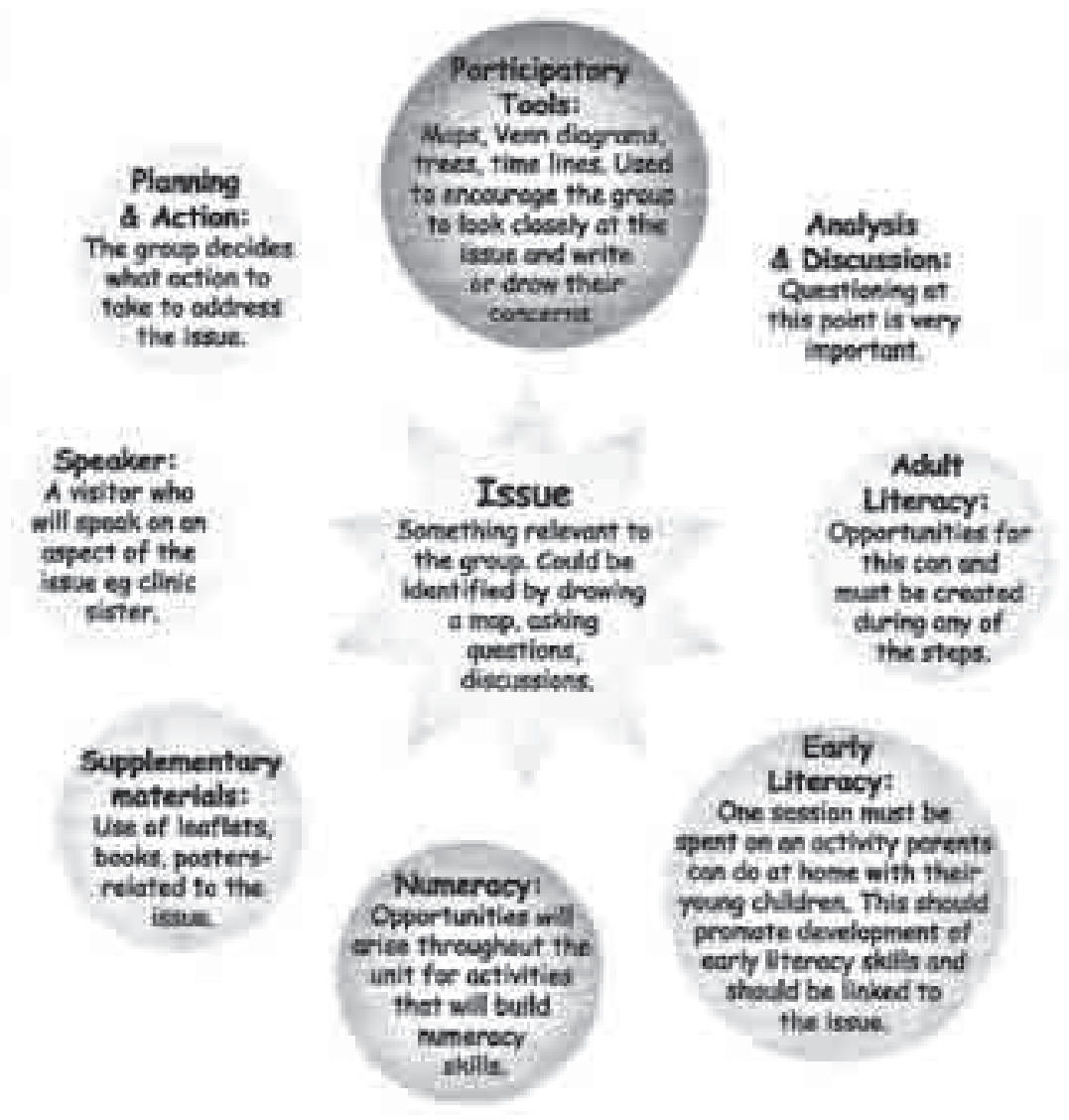

The following provides an explanation of the approach:

Group sessions for adults are held at least twice a week during school terms. Seven or eight sessions form a unit of study and each unit addresses an issue of interest to group members. Topics have 
included Child Protection, Children's Rights and Responsibilities, HIV/Aids, Environment, Journey to Literacy, Caring for our money and Sanitation. The Reflect methodology which promotes participation, discussion and action by group members underpins all sessions. Group sessions include information gained from the participants as well as that introduced by the facilitator. Literacy learning is linked to the discussion. In every unit, i.e., once every seven or eight sessions, there is a session that focuses on children's development. These sessions are linked to the unit topic and provide a time for discussion of how parents can help develop particular skills in their children.

Running through all the group sessions is the belief that reading together as a family is important. The project slogan Masifunde Njengomndeni translates as 'Families Reading Together' and advice is given to parents on how to extend conversations with their children, how to build vocabulary and how to read books with their children in a way that encourages questioning, discussion and interest. Reading is always promoted as a way to enjoy time with children and a way of relaxing with one another (Desmond, 2004: 7-8).

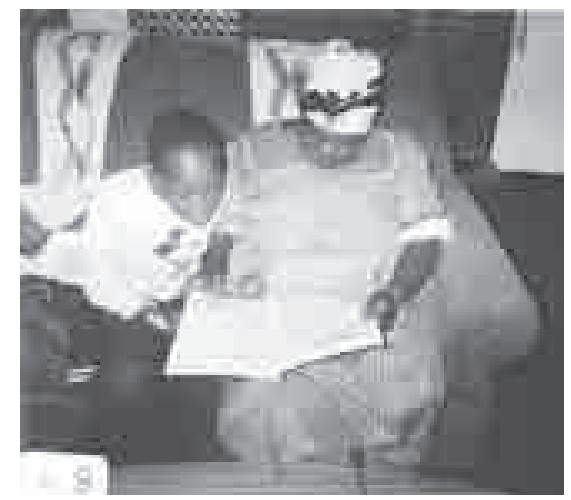

Comment by FLP facilitator: This is my mother and my brother's child. They are using Nolwazi's English book from school. Nolwazi is not good in English so she asks my mother to read to her. She is 10 years old - an only child. She had no teacher for 6 months in her class at Inhlanhleni and then they go to a teacher who was always absent. Her spelling is poor. She thinks in Zulu. For example she would spell 'teacher' 'tisha'. But she is good at maths. 


\section{Home visiting programme}

The Family Literacy Project group sessions include information on topics relevant to the members, such as health, sanitation, budgets, children's rights and child protection as well as aspects of HIV and Aids including voluntary counselling and testing and paediatric care. Group members have been encouraged to read with and to their children, to talk, play and keep journals with them. Group members have reflected on their own experiences of growing up and discussed how they can support their children to have a better chance in life than they did.

The FLP approach and the additional workshops arranged with an early childhood development specialist resulted in a group of women who had learnt a great deal about how to add to conventional ways of supporting children, especially in literacy development. At the end of 2003 they were asked if they would like to share their knowledge and expertise with their neighbours. Most of the women volunteered and the home visiting programme began. For the first year the women made these visits without an expectation of payment or acknowledgement apart from the enjoyment of sharing the pleasure of reading. From the end of 2003, the FLP has secured funding to provide a food voucher for each visit carried out by the group members.

The home visits began with the FLP members reading to their neighbour's children and playing simple games with them. As they exhausted their store of suitable activities, the project once again invited an early childhood development specialist to run a series of workshops. This helped the home visiting group members with ideas for new activities, always using locally or easily obtained materials.

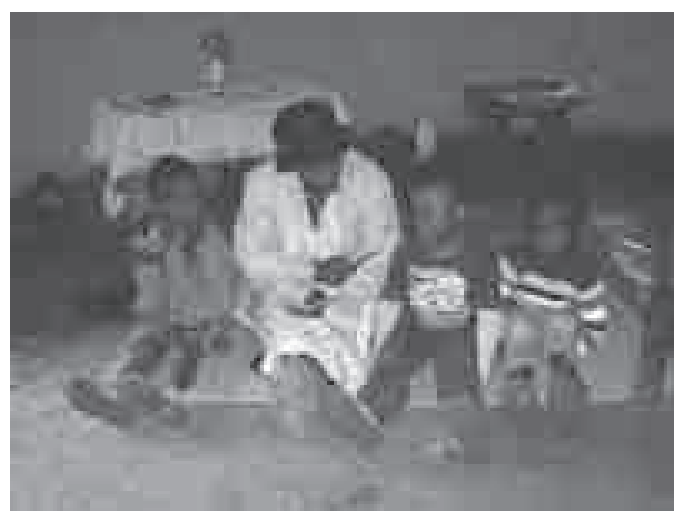


Comment by FLP facilitator: This is a home visit. The learner is reading books to the children. They are the donated First Words in Print books which the children know off by heart already, but they love hearing them over again.

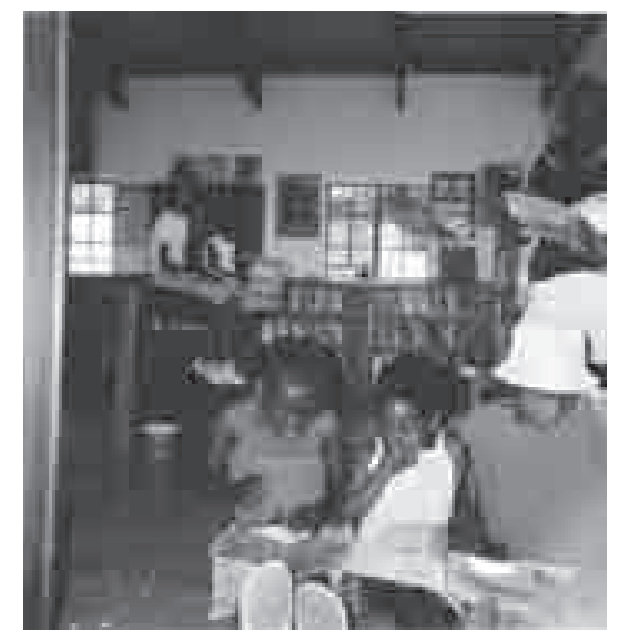

Comment by FLP facilitator These are some of the children visited by our learners in the Home Visiting programme. They live next door to the library. They always come and ask for something to play with. They come and call the learner everyday..... asking for her to read to them. They are like my friends too. They call me "Missy Missy" if they meet me.

In 2005, the project decided to include training on health messages, using the UNICEF supported IMCI programme (Integrated Management of Childhood Illnesses). There are fifteen key messages which have been developed to give those at home the information necessary to help children with simple health problems or prevent these from happening. Very soon the FLP group members were able to include these health messages in their visits. It became apparent, however, that the early childhood development information was delivered in a playful and active way while the delivery of the health messages were delivered in a more didactic way. In keeping with the interactive approach adopted by the project it was important that the visits should be participatory and enjoyed by children and adults. To address this concern, the project has embarked on the development of games and activities to support each health message. 


\section{Books for the community}

At the start of the Family Literacy Project, each group was given a box of books. The group members began by borrowing books to look at with their children. As the adults learnt to read, they read the books and as they became more confident they began to ask for books to read for themselves.

Once again, seeing the pleasure that the group members were getting from reading, the FLP asked if they would like to share this pleasure with others. They asked the women to find out if their neighbours would like to borrow books. Some of the group members took part in a survey to gauge the level of interest in a community library. The response was positive, although the most stated need for a library was that people wanted to visit a place to improve their knowledge; not as much was said about reading for relaxation (Desmond 2005:30).

By 2007 the FLP had established three community libraries. The first was built with the prize money received as part of a Guinness/UDV award; the second library was a donation of a 40 -foot long refurbished container from the Cape Town based NGO Biblionef; and the third was paid for by the Exclusive Books Trust. The books and furniture have all been donated to the FLP. More recently, a fourth community library has been built with donations from a church group in the United States of America.

Two books have been developed by the project to help group members run the libraries. These contain very basic information and cover simple cataloguing, issuing, shelving and membership information. Before these libraries were established, none of the group members had visited or used a library. Each library is now run by the local FLP facilitator and one or two group members who do everything from cleaning to providing activities for children and putting up displays on interesting topics.

The libraries are well used by adults and primary school children. Initially it was difficult to recruit secondary school members and it was not until sessions on topics specifically for that age group were run in the library that they began to join.

In contrast, it has been difficult to keep the numbers of primary school children at a manageable level during the opening times and children's sessions. These children's sessions focus on a theme for six or seven sessions and encourage drawing, discussion, reading and listening. At the one community library the group had to be split into two to accommodate all the children. However all the children continue to come to both sessions and even when half the 
group is sent away, they crowd around the windows to hear the story that they will hear the next day during their own session. After the sessions, the children exchange books and talk about the one that they have read. They are also encouraged to read to someone at home, either a younger sibling or an adult who is prepared to listen to them.

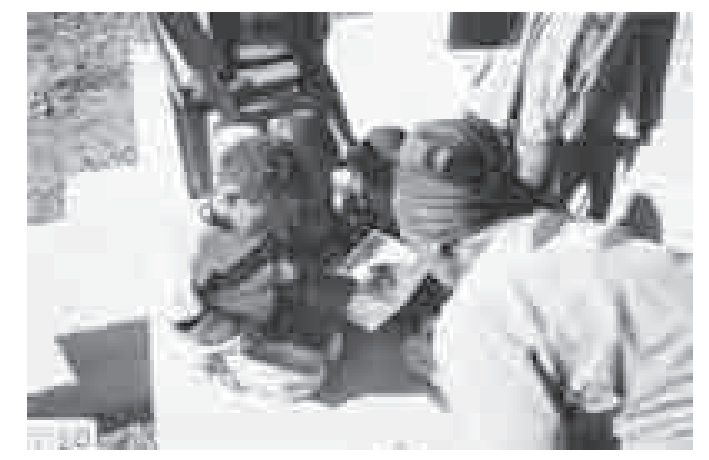

\section{Evaluating the sharing}

In 2006, the facilitators in five sites were given cameras and asked to illustrate the changes in reading habits in their communities and to find out whether reading was seen as a pleasure and not only as a source of knowledge. After taking the first spool, the facilitators met to describe and discuss the photographs. Once the second spool had been taken, all the photographs were displayed on large boards and taken out to each of the groups. The group members were asked to look at the photographs their facilitator had taken, as well as those taken in the other sites. They commented on these before the final display which was at the FLP end of the year event in December 2006. This method ensured participation through the year and at all levels of the project. The evaluation was led by an external evaluator, Jill Frow and the results were published by the FLP (Frow. 2006).

Using the photographs as a prompt, and after some interactive games, the group members were asked for their comments. They were quite forthcoming about books they did not enjoy such as books about war, "big fat books with a lot of writing" and books which were deemed too explicit for young children, such as those showing birth or discussing HIV/Aids. Some people complained of poor eyesight and being too tired at the end of the day to read. As these are women who have to fetch their own water and firewood as well as care for children and do daily housework, it is not surprising that reading comes low down on their list of things to do. However there are many anecdotes told by the facilitators of people, saying that they use books and reading as a way to relax. 
Many of the group members were able to give the title of their favourite book and had suggestions for additional material they would like to see in the library. As the sites are far from any towns it is not surprising that people requested newspapers and magazines. Primary school children are keen members of the libraries and are always asking for different books. As they would like books written in Zulu, this is posing a problem to the FLP as most of the available books are already carried by the libraries.

Adult group members read the easy readers for newly literate adults but there are not many of these available. Many of them borrow books for children and then read them themselves. This is not a problem as they are improving their literacy skills but more books for new readers would be more suitable.

What is evident from the Frow evaluation is that group members "have developed a deep concern for their children and community children to be reading" (Frow, 2006:38). The evaluation report goes on to describe how many children read to their parents as well as parents reading to children. As this quote from a FLP member shows, "when we are finished eating we take books and read and look at the pictures and do homework" (Sibongile Zuma, quoted in Desmond 2004:14), this inter-generational sharing of books may contribute to the family reading time that appears to be growing in some families in the places where the Family Literacy Project is active.

\section{References}

Desmond, A. 2001. The impact of the Family Literacy Project on adults in rural KwaZuluNatal: a case study. M.Ed. dissertation. Durban: University of Natal.

Desmond, S. 2004. Exploring the links between adult education and children's literacy/ education: A case study of the Family Literacy Project, KwaZulu-Natal. Kampala: Pamoja

Desmond, S. 2005. The Family Literacy Project: Now we are almost six. Durban: Family Literacy Project.

Desmond, A. 2007. Doctoral thesis in progress

Dockrell, J. Stuart, King, D. 2004. Supporting early oral language skills. http://www.literacytrust.org.uk.uk/Pubs/dockrell.html Accessed on 1 February 2007

Frow, J. 2006. Family Literacy Project Evaluation 2006. Durban. Family Literacy Project. Also available on www.familyliteracyproject.co.za

Khulisa Management Services 2000. National Early Childhood Development Pilot Project: Phase Three Research Report, Khulisa Management Services, Johannesburg.

KwaZulu-Natal Municipal Portfolio. 2005. Sisonke District Municipality. www.kzntopbusiness.co.za/2005/KZN-Municipalities Accessed 13 March 2007

National Literacy Trust (undated) Family literacy document. http://www.literacytrust.org. uk/Database/familitindex.html Accessed, February 2007

Richter, L. 2006. Personal communication with the author. 